documentation and prevention of a global public health problem. Bull World Health Organ. 2005;83(11):853-6.

3. Idris AH, Berg RA, Bierens J, Bossaert L, Branche CM, Gabrielli A, et al. Recommended guidelines for uniform reporting of data from drowning: the "Utstein style". Circulation. 2003;108(20):2565-74.

4. Sempsrott J. Drowning. In: Hawkins SC, ed. Wilderness EMS. Philadelphia, PA: Wolters Kluwer; 2018.

5. Schmidt AC, Sempsrott JR, Hawkins SC, Arastu AS, Cushing TA, Auerbach PS. Wilderness medical society clinical practice guidelines for the treatment and prevention of drowning: 2019 Update. Wilderness Environ Med. 2019;30(4S): S70-86.

6. Szpilman D, Webber J, Quan L, Bierens J, Morizot-Leite L, Langendorfer SJ, et al. Creating a drowning chain of survival. Resuscitation. 2014;85(9):1149-52.

\section{In Reply to Dr Sempsrott et al}

\section{To the Editor:}

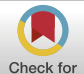

We appreciate the comments of Sempsrott et $\mathrm{al}^{1}$ regarding the article "Flush Drowning as a Cause of Whitewater Deaths", and find their observations terminologically insightful. We agree that adding qualifiers to the term drowning, such as "dry, secondary, or near" sometimes adds more confusion than clarity. Our use of "flush drowning" deviates from the current definition of "drowning" in several respects; for instance, flush drowning in our definition is always fatal, whereas most uses of the word "drowning" involve variable outcomes. Human death most often is influenced by preexisting comorbidities that may interact with various triggering or enhancing environmental precipitants, any of which may or may not be anticipated or recognized by a medical examiner. Diagnostic uncertainty exists in many deaths, and in the case of lethal drowning, pathologists recognize the inherent risk of missing important confounders, such as seizures, intoxicants, trauma, or hypothermia. $^{3-5}$

Although we agree with most of the statements of Sempsrott et al, we would like to make several other comments regarding the letter. First, our usage of the term "flush drowning" was driven primarily by its long-standing prior establishment and name recognition within the whitewater community, which is our target audience. As for the general suitability of the phrase in the medical literature, not only does use of "drowning" rightly raise questions, but the qualifier "flush" is even more problematic because it implies that flush drownings only occur in "flushing" flows, which is incorrect. In fact, it is our opinion that water temperature has a profound effect on flush drowning.

Second, because drowning definitions variably refer to immersion or submersion in a liquid medium with respiratory impairment as required substrates, most lack further specificity as to the antecedents leading to respiratory compromise. In fatal drownings, many current definitions, taken literally, could suggest any "in water" death is a drowning, considering that all death involves respiratory impairment. Although this may or may not be the intention of the epidemiologists, such an application does little to differentiate the primary or sequential physiologic events leading to respiratory compromise. In regard to cold water immersion, we have suggested lethal arrhythmias may be an important cause of death. As such, if the head is never submersed and there is no head-abovewater aspiration, the respiratory compromise could be a secondary effect of immersion-produced arrythmia. Other similar potentially lethal effects of cold-water immersion that do not necessarily require aspiration or head submersion may include hypothermia, hypertension-induced vascular catastrophe, and post-rescue collapse. Although such events may still be considered a drowning in the strictest sense, preventing adverse outcomes may require varied approaches.

Lastly, the suggestion by Sempsrott et al that flush drownings be called "fatal drowning due to X," where " $X$ " presumably represents the antecedent cause of the drowning, may be attractive in certain applications, but such phrasing would be largely a semantic gesture as applied to flush drowning. Until we can differentiate which deaths in this cohort directly result from cold water immersion versus other causes, $\mathrm{X}$ will remain elusive. This confusion is further compounded because secondary submersion or aspiration events can follow any cause of death. These constructs have always presented problems for physicians signing death certificates. ${ }^{3,5}$ For instance, does the fisherman who is standing in knee-deep water and is fatally struck by lightning represent a fatal drowning secondary to lightning strike? Does this hold true even if the victim's head never becomes submersed and no aspiration occurs? Likewise, does the deceased jogger found face up in $10 \mathrm{~cm}$ (4 in) of water with an intoxicant in the bloodstream represent drowning or something else? With respect to flush drowning, because of the inability to reliably define $\mathrm{X}$, we arrive back at "fatal drowning due to flush drowning," or whatever phrase one decides to call this amorphous group. Although we agree new terminology is required, until we can reliably differentiate $X$, this effort may offer little enlightenment, although it may appease the semasiologists. 


\section{References}

1. Sempsrott JR, Hawkins SC, Graham DA, Davis CA, Abo BN, Schmidt AC. In response to flush drowning as a cause of whitewater deaths: targeting prevention with uniform definitions. Wilderness Environ Med. 2020;31(3):371-2.

2. Farstad DJ, Luttrell JM. Flush drowning as a cause of whitewater deaths. Wilderness Environ Med. 2020;31(1): $11-5$.

3. Armstrong EJ, Erskine KL. Investigation of drowning deaths: a practical review. Acad Forensic Pathol. 2018;8(1):8-43.

4. Otavio Savassi Rocha L. Death certificate: admitting uncertainty. Autops Case Rep. 2018;8(2):e2018024.

5. Smith Sehdev AE, Hutchins GM. Problems with proper completion and accuracy of the cause-of-death statement. Arch Intern Med. 2001;161(2):277-84.

\section{First Aid for a Drowning Child}

To the Editor:

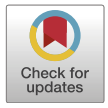

I read with interest the update by Schmidt et $\mathrm{al}^{1}$ to the original Wilderness Medical Society practice guidelines ${ }^{2}$ for treatment and prevention of drowning. In the guidelines, based on extensive analysis of the literature on the subject, useful indications are given on the modalities and effectiveness of rescue interventions.

I note that in the literature there are no reports of a possible modality of intervention easily achievable in children. I would suggest including this, based on a personal experience, even if limited to a single case.

\section{Case Report}

A child was found in a seawater pool, floating motionless, upper limbs open laterally, face up, open mouth at the water's surface, and eyes open with a vague appearance.

He was promptly removed from the water and found to be atonic, unconscious, and apneic (pulses were not checked at that moment). He was immediately raised upside down by the ankles and held that way. $\mathrm{He}$ instantly emitted water, which ceased after a few seconds. The child (4.5 y, weight $19 \mathrm{~kg}$ ) recovered promptly: he began to breathe, although dyspneic and coughing for several seconds. There was no vomit. Still atonic, but with a regular heartbeat, he was laid on a camp bed and regained consciousness, although he was hyporesponsive and slightly confused for several minutes. No other resuscitation maneuvers were necessary. A repetition of the upside-down maneuver, less than 2 min after the first one, did not produce any additional emission.

The child reported no consequences, with normal general and neurological examination.
It is not possible to know how long he was in the water; it is only known that he had been out of sight for several minutes. All available data indicated an accidental fall into the pool. It was confirmed that he did not have previous pathologies. The temperature of the pool water was estimated to be higher than $20^{\circ} \mathrm{C}$ (southern Sardinia, Italy, beginning of August; usually around $25^{\circ} \mathrm{C}$ ).

It is estimated that the child emitted much more than 50 $\mathrm{mL}$ of water. The puddle on the floor did not allow a correct evaluation of the quantity of water.

\section{Discussion}

The maneuver was simple and the effect rapid, although success could have been favored by a short submersion time, with a limited period of hypoxia. However, the condition of the child when he was in water suggests no less than 1 to 2 min of submersion.

\section{WATER IN THE AIRWAYS}

One objection to the use of the upside-down lifting maneuver could be that the water is rapidly absorbed into the blood $^{3}$ so that airways may be empty. This is more likely to occur when some time passes between recovery of the person from the water and transport to a place where it is possible to start rescue maneuvers, during which time the mouth is out of the water. Instead, in the situation reported, the water may have continued to enter the child's open mouth as he was pulled up.

I believe it is unlikely that the emitted water came partly from the stomach because this would require overcoming the lower esophageal sphincter. Without subdiaphragmatic pressure, this is difficult to initiate. In addition, the issuance of water was so immediate as to suggest a provenance from open routes. Likewise, the effect on the child's condition was so rapid as to suggest prompt resumption of oxygenation. On the other hand, the amount of water emitted was estimated to be greater than what would have been contained in the airways above the larynx if the child had been in a laryngospasm condition.

In lifting upside down, the abdominal organs apply pressure on the diaphragm and then on the thoracic cage; it should be verified with further studies whether this can also cause a "squeezing" effect, albeit slight, on the lungs, which could facilitate the elimination of water or reduce edema.

\section{AIR INSUFFLATION WITH WATER IN THE AIRWAYS}

It has been reported that "there is evidence that water does not obstruct ventilation... even when large amounts of water are present within the trachea and bronchi, it is possible to oxygenate patients." ${ }^{4}$ However, it is difficult to 